In Focus Article

\title{
Thrombosis: A Major Contributor to Global Disease Burden*
}

Gary E. Raskob, PhD ${ }^{1}$ Pantep Angchaisuksiri, $\mathrm{MD}^{2}$ Alicia N. Blanco, PhD ${ }^{3}$ Harry Büller, MD, PhD Alexander Gallus, MD ${ }^{5}$ Beverley J. Hunt, MD ${ }^{6}$ Elaine M. Hylek, MD ${ }^{7}$ The Lord Kakkar, MBBS, PhD, FRCS 8 Stavros V. Konstantinides, MD, PhD, FESC ${ }^{9}$ Micah McCumber, MS ${ }^{1}$ Yukio Ozaki, MD, PhD ${ }^{10}$ Aaron Wendelboe, PhD $^{1}$ Jeffrey I. Weitz, MD ${ }^{11}$; ISTH Steering Committee for World Thrombosis Day

${ }^{1}$ College of Public Health, University of Oklahoma Health Sciences

Address for correspondence Gary E. Raskob, PhD, College of Public Center, Oklahoma City, Oklahoma

2 Faculty of Medicine, Ramathibodi Hospital, Mahidol University, Health, University of Oklahoma Health Sciences Center, 801 NE 13th Bangkok, Thailand

${ }^{3}$ Division of Hemostasia, Academia Nacional de Medicina, Buenos Aires, Argentina

${ }^{4}$ Department of Vascular Medicine, Academic Medical Center, Amsterdam, The Netherlands

${ }^{5}$ Department of Hematology, SA Pathology, Flinders Medical Center, Adelaide, South Australia, Australia

${ }^{6}$ Thrombosis and Thrombophilia Centre, Guy's and St Thomas NHS Foundation Trust, London, United Kingdom

7 Section of General Internal Medicine, Department of Medicine, Boston University School of Medicine, Boston, Massachusetts

${ }^{8}$ Thrombosis Research Institute, London, United Kingdom

${ }^{9}$ Center for Thrombosis and Hemostasis, University Medical Center, Johannes Gutenberg University, Mainz, Germany

10 Department of Laboratory Medicine, University of Yamanashi, Yamanashi, Japan

11 Thrombosis and Atherosclerosis Research Institute, and McMaster University, Hamilton, Ontario, Canada,

Reprinted with permission from: ISTH Steering Committee for World Thrombosis Day. Thrombosis: a major contributor to global disease burden. J Thromb Haemost 2014;12:1580-1590; DOI: $10.1111 /$ jth.12698. (02014 International Society on Thrombosis and Haemostasis.

Semin Thromb Hemost 2014;40:724-735.
Abstract
Keywords
- thrombosis
- venous thrombosis
- deep vein thrombosis
- pulmonary embolism
- disease burden
- global health

Thrombosis is a common pathology underlying ischemic heart disease, ischemic stroke, and venous thromboembolism (VTE). The Global Burden of Disease Study 2010 (GBD 2010) documented that ischemic heart disease and stroke collectively caused one in four deaths worldwide. GBD 2010 did not report data for VTE as a cause of death and disability. We performed a systematic review of the literature on the global disease burden due to VTE in low-, middle-, and high-income countries. Studies from Western Europe, North America, Australia, and Southern Latin America (Argentina) yielded consistent results with annual incidences ranging from 0.75 to 2.69 per 1,000 individuals in the population. The incidence increased to between 2 and 7 per 1,000 among those 70 years of age or more. Although the incidence is lower in individuals of Chinese and Korean ethnicity, their disease burden is not low because of population aging. VTE associated with hospitalization was the leading cause of disability-adjusted-life-years (DALYs) lost in low- and middle-income countries, and second in
Issue Theme Hot Topics Vl; Guest Editor, Emmanuel J. Favaloro, PhD, FFSc (RCPA). published online October 10, 2014
2014 Thieme Medical Publishers, Inc., 333 Seventh Avenue, New York, NY 10001, USA. Tel: +1(212) 584-4662.
License terms

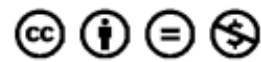


high-income countries, responsible for more DALYs lost than nosocomial pneumonia, catheterrelated blood stream infections, and adverse drug events. VTE causes a major burden of disease across low-, middle-, and high-income countries. More detailed data on the global burden of VTE should be obtained to inform policy and resource allocation in health systems, and to evaluate if improved utilization of preventive measures will reduce the burden.

A doubling of life expectancy and quadrupling of the world population during the 20th century have been associated with a transition from infectious to noncommunicable diseases as the major cause of death and disability worldwide. $^{1-3}$ Cardiovascular disease is a leading contributor to the burden caused by noncommunicable diseases. Thrombosis is the most common underlying pathology of the three major cardiovascular disorders: ischemic heart disease (acute coronary syndrome), stroke, and venous thromboembolism (VTE).

The Global Burden of Diseases, Injuries, and Risk Factors Study (GBD Study), which was initiated by the World Health Organization (WHO) and the World Bank, is a systematic scientific investigation aimed at quantifying the comparative magnitude of health loss due to diseases, injuries, and risk factors by age, sex, and geographic region throughout the world. $^{3-5}$ The most recent version of this effort, GBD 2010, documents the number of deaths from 235 causes from 1990 through 2010, using data from 187 countries and 21 regions; these regions are grouped further into 7 super-regions. ${ }^{4,5}$ The study also provides estimates of the years of life lost (YLL) due to premature mortality, the years lived with disability (YLD), and the disability-adjusted life years (DALYs). ${ }^{4,5}$ DALYs estimate how many years of healthy life are lost because of premature death or nonfatal illness or disability, and are calculated as the sum of YLL and YLD. ${ }^{6}$

GBD 2010 documented 52.8 million deaths globally in $2010 .^{3}$ Noncommunicable disease accounted for 34.5 million deaths, or two out of every three deaths. ${ }^{3}$ Ischemic heart disease ( 7.0 million deaths) and stroke (5.9 million deaths) collectively caused one in four deaths worldwide. ${ }^{3}$ The 7.0 million deaths from ischemic heart disease represent a $35 \%$ increase since 1990 . About half of all stroke deaths were from ischemic stroke, which is caused by thrombosis. The 2.8 million deaths from ischemic stroke represent a $25 \%$ increase since 1990. Although there is substantial regional variation, ischemic heart disease ranks as the number one or two causes of YLL in 13 of the 21 regions, and ranks in the topfive causes of death in 17 regions. ${ }^{3}$ Stroke ranks as the first or second cause of YLL in 8 regions, and is in the top-five causes in 14 regions. ${ }^{3}$ Ischemic heart disease was the leading cause of DALYs lost worldwide in 2010 (up from fourth rank in 1990, an increase of 29\%), and stroke was the third leading cause (up from fifth rank in 1990, an increase of $19 \%$ ). ${ }^{6}$ More than $60 \%$ of new strokes and $45 \%$ of deaths from stroke occur in individuals less than 75 years of age. ${ }^{7}$

GBD 2010 clearly documents the major impact of arterial thrombosis on global disease burden because it is the pathological mechanism underlying most cases of ischemic heart disease and ischemic stroke. However, the study does not report data for VTE as a specific cause of death and disability. A cursory review of the literature from Western Europe and North America suggests that VTE is a major contributor to the burden from noncommunicable diseases. For example, Cohen and colleagues used an incidence-based epidemiology model to estimate the number of nonfatal symptomatic VTE events, which includes both deep vein thrombosis (DVT) and pulmonary embolism (PE), and the number of VTE-related deaths across the European Union in 2004 (population, 454.4 million). ${ }^{8}$ The results yielded estimates of 684,019 DVT events; 434,723 PE events; and a total of 543,454 VTErelated deaths. ${ }^{8}$ In the United States, investigators from the Centers for Disease Control and Prevention used data from the National Hospital Discharge Survey to estimate that there were an average of 547,596 adult hospitalizations with a diagnosis of VTE each year during 2007 to 2009 among the population of 301 to 307 million. ${ }^{9}$ If VTE causes a proportionate burden of disease across the other global regions, it would be highly ranked in the causes of death and DALYs worldwide. Given that much of the mortality and morbidity from VTE is potentially preventable, ${ }^{10-13}$ data on the disease burden are important for health systems and policy makers for planning resource allocation, both for health care delivery and for setting research priorities.

We therefore performed a systematic review of the literature on the global burden of disease due to VTE. The objective was to review the evidence for disease burden in each of the geographic regions specified in the GBD Study 2010, using the variables of annual incidence rate (number of new cases each year per 1,000 population at risk), prevalence (proportion of the population with the condition at a point in time), annual number of deaths, and DALYs.

\section{Methods}

\section{Literature Search and Review}

A computer search of the literature was performed using OVID Medline, OVID Medline In-Process and Other NonIndexed Citations, and EMBASE, from inception of these databases to May 2014. We used the disease-related key words venous thromboembolism, deep vein thrombosis, venous thrombosis, vein thrombosis, thrombophlebitis, pulmonary embolism, and lung embolism, together with the additional key words incidence, prevalence, mortality, case fatality, morbidity, surveillance and epidemiology, years lived with disability (YLD), and disability-adjusted life years (DALY), to search the titles and abstracts of articles in these databases. We also reviewed the bibliographies of published 
articles. We excluded nonhuman studies, case reports, and clinical trials, as well as nonrelevant publication types, including reports of clinical conferences and editorials. We also excluded articles published in languages other than English, and the current report is confined to the literature published in English. The identified citations from each database were exported to an ENDNOTE library where the citations were de-duplicated. The merged list of citations was exported to a word document that included citation number, title, list of authors, the full abstract, and the journal citation.

The abstracts were reviewed independently by two reviewers (A.W. and G.E.R.) who categorized them according to the level of evidence as level A, level B, or other; disagreements were resolved through discussion and consensus. Level A evidence was defined as population-based estimates of the parameters of the disease burden (incidence, prevalence, number of deaths, DALYs) in the general population (age 18 years or older) derived from either population-based cohort studies or from analysis of national health system databases or private health insurance claims data within a defined population, or derived using a combination of the former methods with appropriate epidemiologic modeling methods. Level B evidence was defined as estimates of the burden in specific subpopulations such as the elderly, pregnancy, etc., using the same methods described for level A. The category of "other" evidence included all other study designs without a defined population to derive the disease burden parameters, such as single hospital base cohort studies or record review, and autopsy studies. Population-based mortality studies based on hospital discharge or other databases, or health department death certificate data, were also assigned to the category of "other." This article focuses on the level A evidence for overall disease burden according to global region. Selected level B evidence on the relationship between age and disease burden were also included where relevant. The evidence categorized as "other" was not systematically reviewed.

To simplify comparison of incidence results across studies and between global regions, all incidence rates were converted to a rate per 1,000 individuals per year.

\section{Results}

\section{Literature Search}

The computerized literature search identified a total of 9,603 citations. Of these citations, 8,817 (92\%) were in English. After the de-duplication check, a total of 8,702 citations remained for review.

The two independent reviewers were in agreement on the classified level of evidence for 8,671 (99\%) of the 8,702 reviewed citations; the remaining 31 citations were classified after discussion and consensus between the reviewers. The final classification designated 29 citations as level $\mathrm{A}$ evidence, ${ }^{14-42} 29$ as level B evidence, ${ }^{43-71}$ and the remainder as other. Most of the level A studies evaluated the incidence of VTE or its components, DVT and/or $\mathrm{PE}^{14-40}$; two studies evaluated the prevalence of VTE. ${ }^{41,42}$

\section{Incidence of Venous Thromboembolism}

The results of the studies classified as level A evidence of incidence are summarized in -Table 1. This evidence comes from only two of the seven global super-regions designated by GBD 2010: "high income" and "Southeast Asia, East Asia, and Oceania." Within the high-income super-region, 11 level A studies were from the region of Western Europe, ${ }^{8,14-23}$ 10 were from North America, 2 were from Australasia (both from Australia), ${ }^{33,34} 1$ was from the region of Southern Latin America (Argentina), ${ }^{35}$ and 1 was from the Asia Pacific region (Korea). ${ }^{36}$ The three level A studies from the super-region of "Southeast Asia, East Asia, and Oceania" all came from the region of East Asia ${ }^{37-39}$ (two studies from Hong Kong and one from Taiwan).

The relationship between increasing age and the incidence of VTE was evaluated in several of the level A studies. $9,19,21,22,24,30,32,35-38,40$ The results of these studies are summarized in - Table 2.

The level B studies evaluated the incidence of VTE in various subpopulations, such as during pregnancy or the postpartum period, ${ }^{43-54}$ males or females of selected age categories, ${ }^{55-64}$ subgroups with or without selected risk factors or comorbidities, ${ }^{65-70}$ or special categories of thrombosis. ${ }^{71}$ All, but one, of the level B studies came from the super-region designated high income; the exception was from sub-Saharan Africa (South Africa). ${ }^{51}$ Within the highincome super-region, 14 of the level B studies were from the region of Western Europe, 43,44,46,49,54,55,57-59,61-63,65,69 11 were from North America, ${ }^{45,47,50,52,56,60,64,67,68,70,71} 2$ were from Australasia (both from Australia), ${ }^{48,53}$ and 1 was from the high-income Asia Pacific region (Japan). ${ }^{66}$

\section{Prevalence of Venous Thromboembolism}

Two studies were identified that evaluated the prevalence of VTE; both were done in the United States by the same investigators. ${ }^{41,42}$ The national prevalence of VTE was determined during the 5-year period from 2002 through 2006 using a health insurance claims database of 12.7 million enrollees that included both private insurance claims and Medicare claims. The prevalence of VTE was 3.2 per 1,000 enrollees in 2002, and 4.2 per 1,000 enrollees in $2006 .{ }^{41}$ Among patients 65 years of age or older, the prevalence in 2006 was 13.8 per 1,000 enrollees, compared with 2.3 per 1,000 enrollees in those less than 65 years of age. ${ }^{41}$ The authors used the 2006 data to project the U.S. national prevalence as 0.95 million cases, and to project the future prevalence in 2050 to be 1.82 million cases. ${ }^{41}$ The second study found that the prevalence of VTE was highest in African American males, followed by Caucasian males, Caucasian females, and African American females. ${ }^{42}$ Hispanic individuals of both sexes had lower prevalence. ${ }^{42}$

\section{Disability-Adjusted Life Years}

Our search identified two studies that evaluated disease burden in terms of DALYs. ${ }^{72,73}$ The methodologically strongest was the study by Jha and colleagues, as part of the WHO Patient Safety Program. ${ }^{72}$ This study used analytic modeling to estimate the incidence rates of VTE, annual number of 


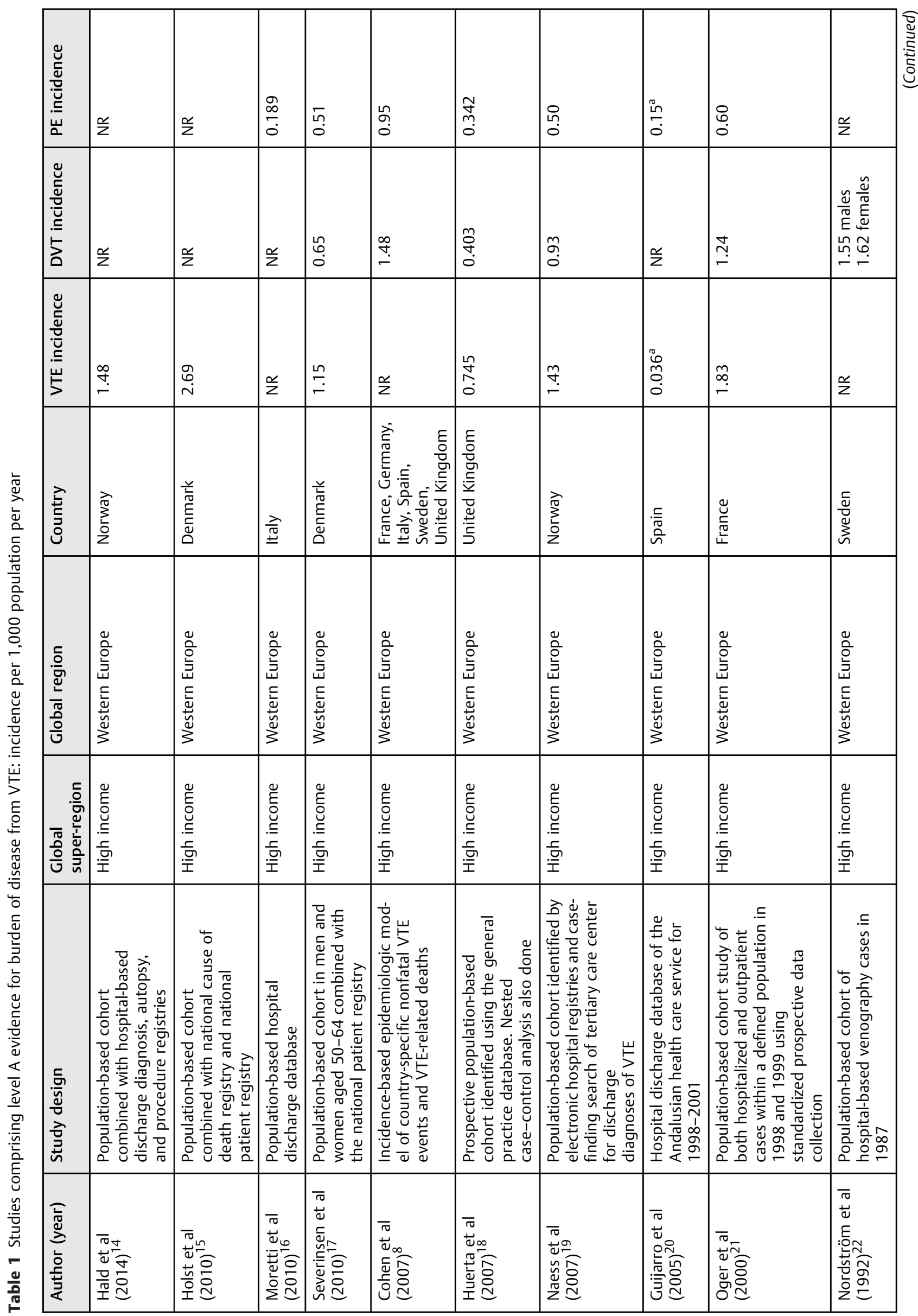




\begin{tabular}{|c|c|c|c|c|c|c|c|c|c|c|}
\hline 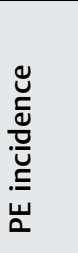 & 兴 & $\stackrel{\text { qq }}{\circ}$ & 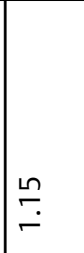 & 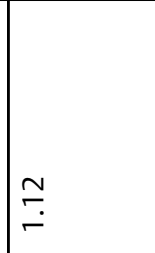 & $\stackrel{\text { qq }}{\circ}$ & $\begin{array}{l}\stackrel{0}{0} \\
\text { m. } \\
0\end{array}$ & 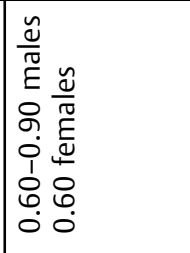 & 兰 & 帛 & 兰 \\
\hline 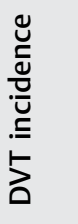 & 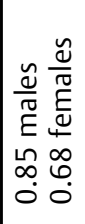 & 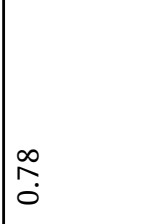 & 苂 & $\frac{v}{z}$ & 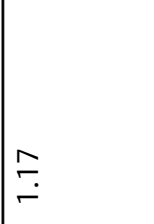 & 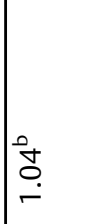 & $\frac{v}{z}$ & 兰 & $\stackrel{\infty}{\stackrel{\infty}{0}}$ & 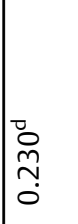 \\
\hline 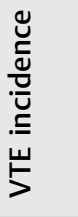 & 兴 & $\stackrel{\underset{N}{\sim}}{\sim}$ & 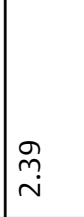 & 竞 & $\underset{-}{-}$ & $\begin{array}{l}\text { ô } \\
\text { m. } \\
-\end{array}$ & 学 & $\frac{\breve{o}}{\frac{0}{0}}$ & 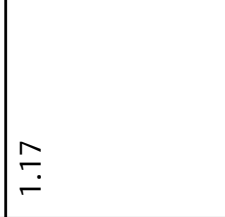 & $\stackrel{\stackrel{c}{z}}{2}$ \\
\hline 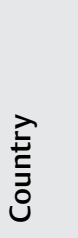 & 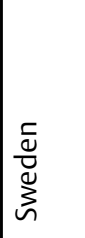 & 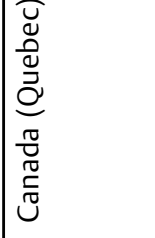 & 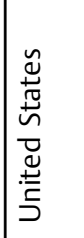 & 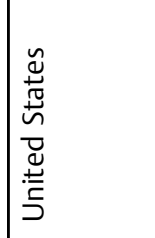 & 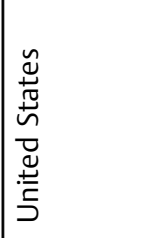 & 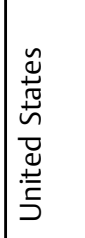 & 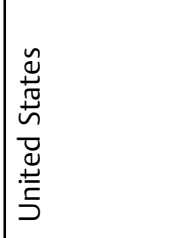 & 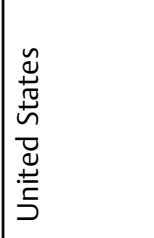 & 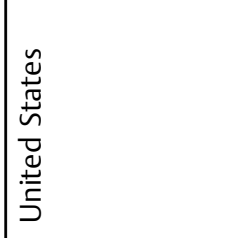 & 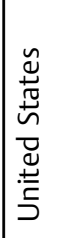 \\
\hline 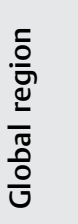 & 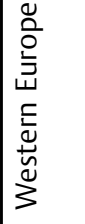 & 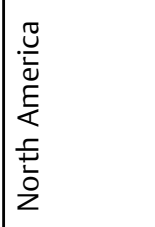 & 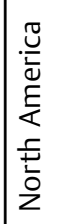 & 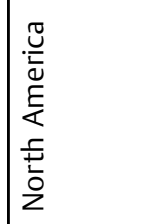 & 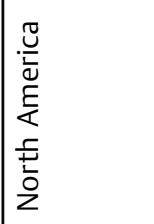 & 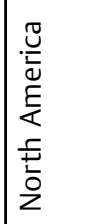 & 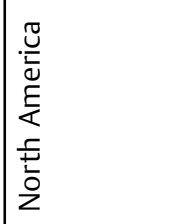 & 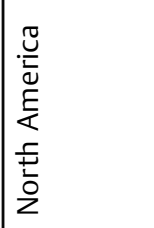 & 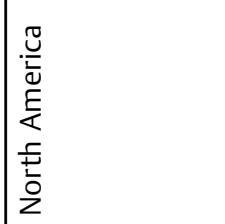 & 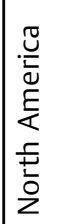 \\
\hline 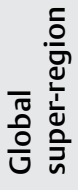 & 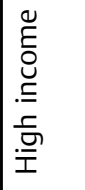 & 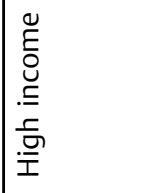 & 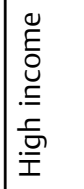 & 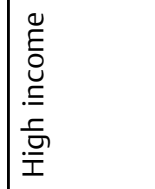 & 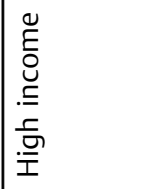 & 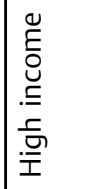 & 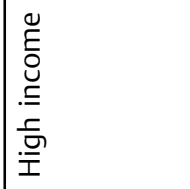 & 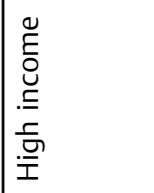 & 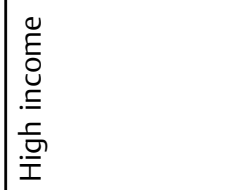 & 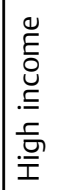 \\
\hline 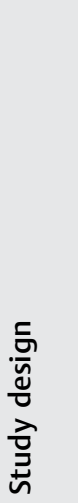 & 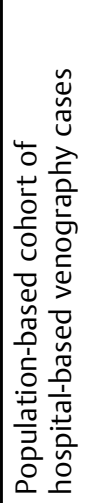 & 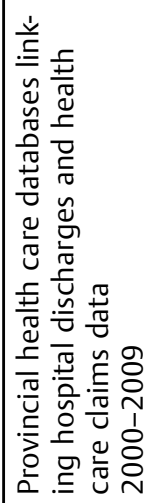 & 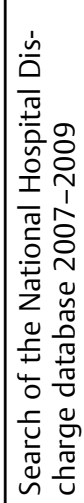 & 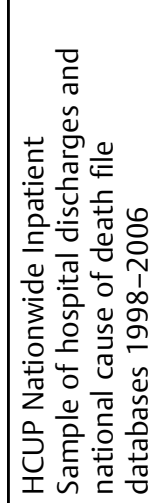 & 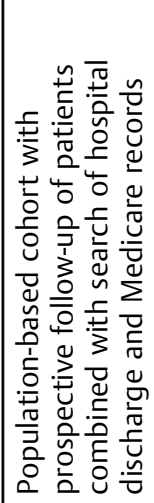 & 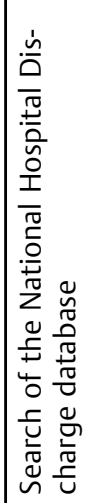 & 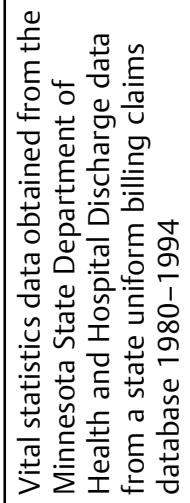 & 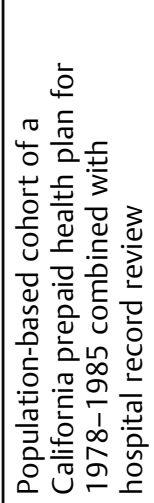 & 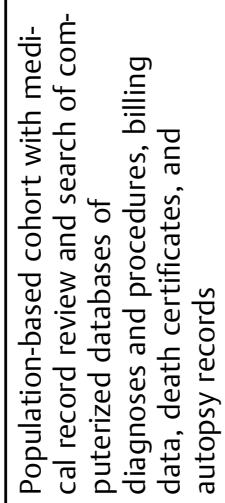 & 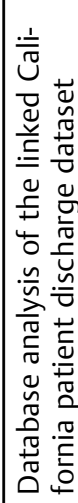 \\
\hline 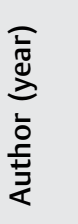 & 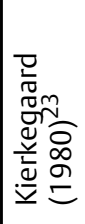 & 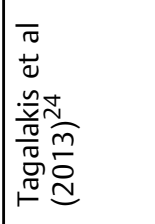 & 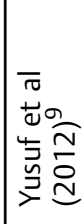 & 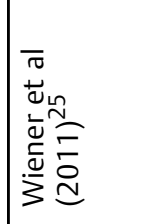 & 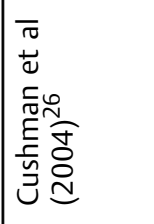 & 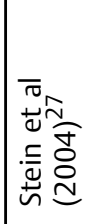 & 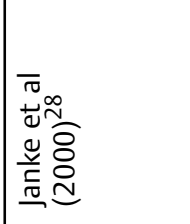 & 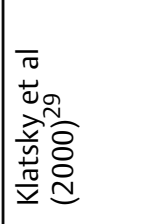 & 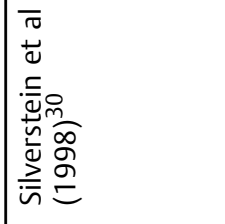 & 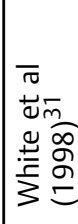 \\
\hline
\end{tabular}


In Focus Article: Thrombosis-Global Burden Raskob et al. 729

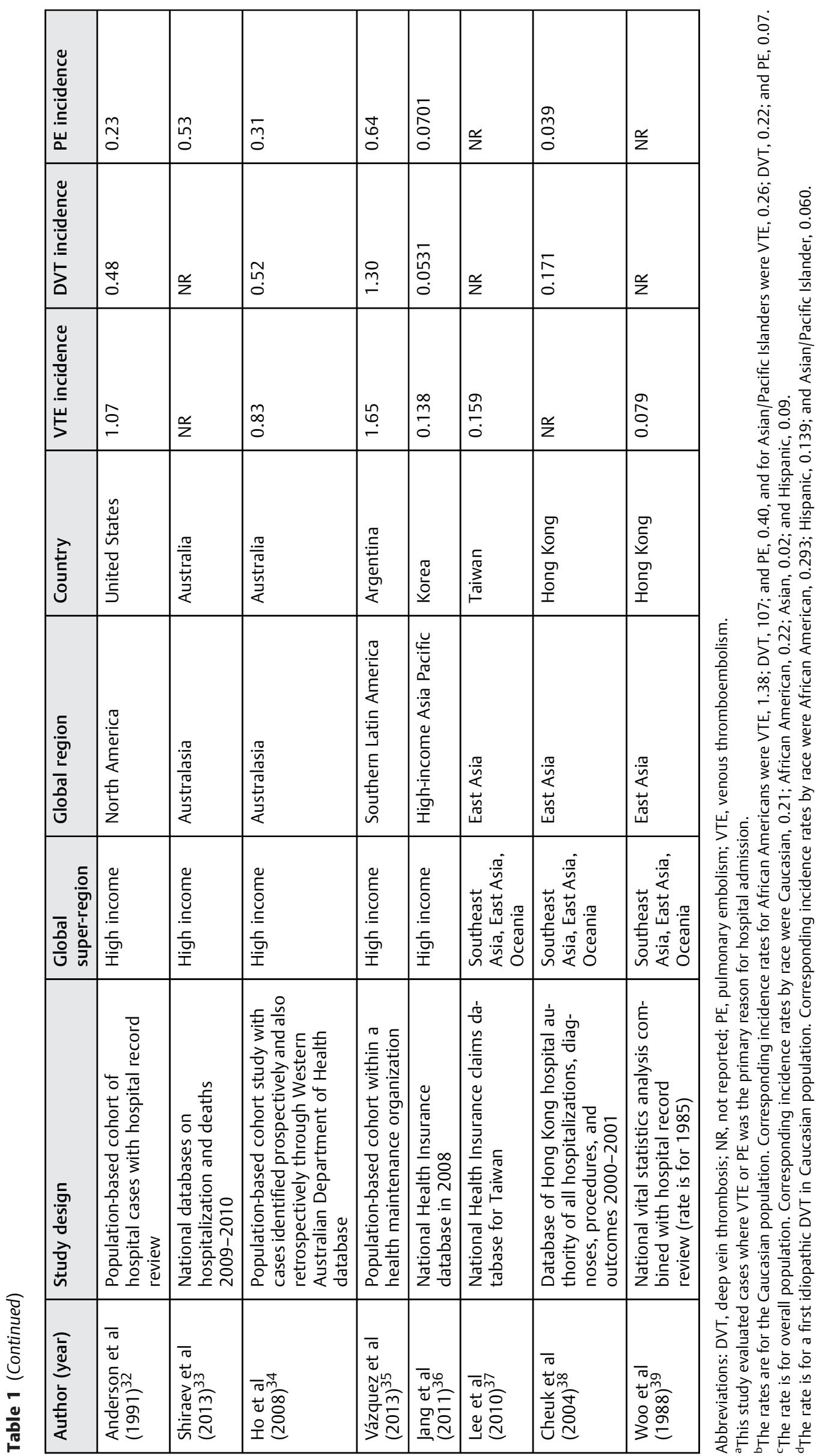




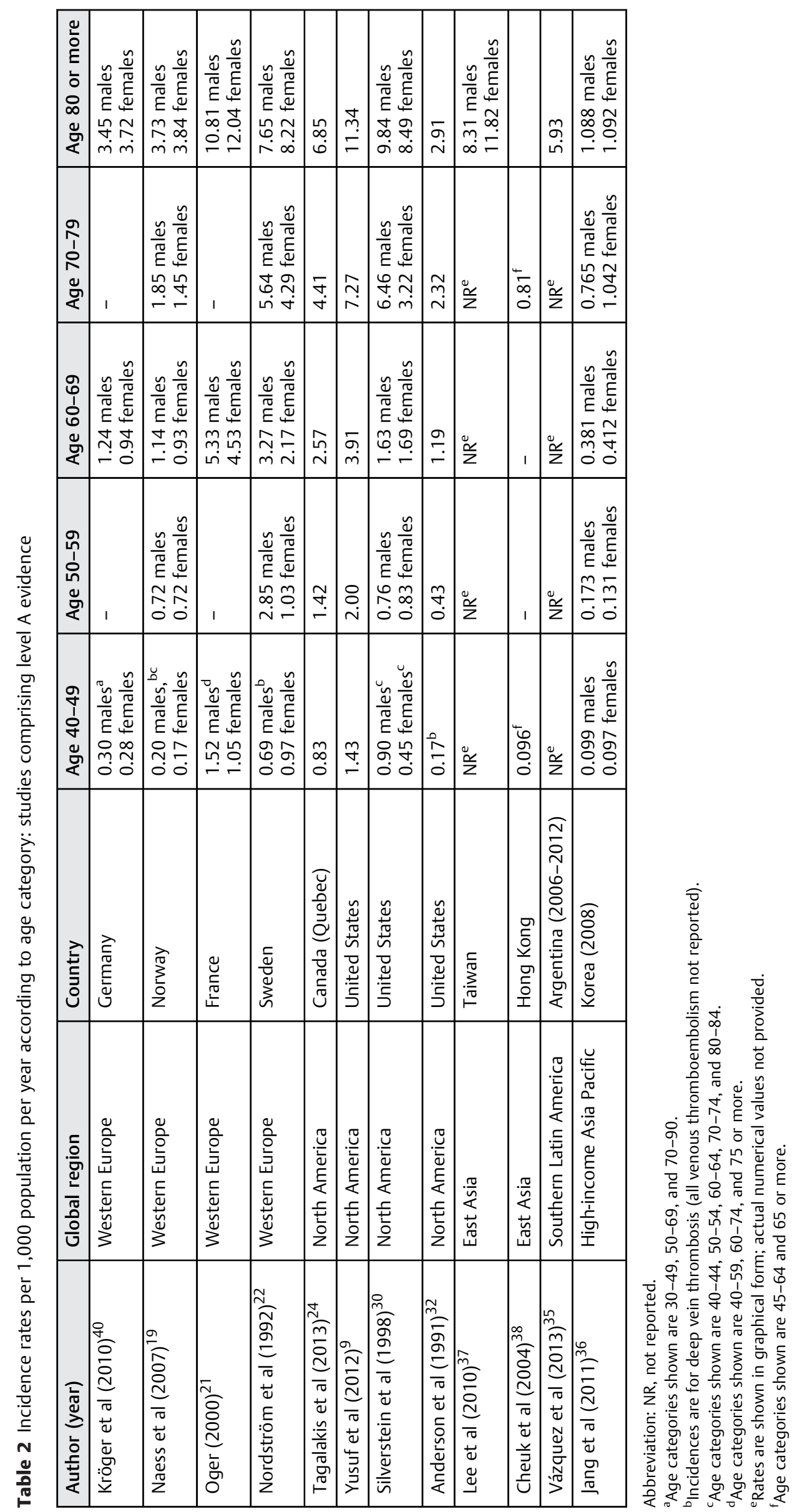


cases, and DALYs from VTE associated with hospitalization in high-, middle-, and low-income countries. ${ }^{72}$ The data for the modeling were generated from two sources: an extensive literature review and epidemiologic studies commissioned by the WHO, which were conducted in 26 hospitals across 8 lowand middle-income countries in the Eastern Mediterranean and the regions of North Africa (Egypt, Jordan, Kenya, Morocco, South Africa, Sudan, Tunisia, Yemen), ${ }^{74}$ and in 35 hospitals across 5 countries in Latin America (Argentina, Colombia, Costa Rica, Mexico, and Peru). ${ }^{75}$ This approach enabled the authors to estimate the number of VTE events associated with hospitalization during 2009 for 117.8 million hospitalizations among 1.1 billion citizens of high-income countries, and for 203.1 million hospitalizations among 5.5 billion citizens of low- and middle-income countries. ${ }^{72,74,75}$

The study reported incidences of VTE per 100 hospitalizations of 3.3 (95\% confidence interval [CI], 1.9-4.8) in highincome countries, and 3.0 (95\% CI, 1.0-4.8) in low- and middle-income countries. ${ }^{72}$ The estimated annual number of cases of VTE was 3.9 million (95\% CI, 1.9-6.3) for the highincome countries, and 6.0 million ( $95 \% \mathrm{CI}, 1.2-12.8)$ for the low- and middle-income countries. VTE was the leading cause of hospital-related DALYs lost overall, being responsible for a full one-third $(7,681)$ of the total of 22,644 DALYs, and VTE accounted for more DALYs lost than nosocomial pneumonia, catheter-related blood stream infections, and adverse drug events. ${ }^{72}$ VTE was the leading cause of DALYs lost in the lowand middle-income countries, and ranked second in the highincome countries. ${ }^{72}$ Premature death was the source of $64 \%$ of the DALYs lost in high-income countries and for $66 \%$ of the DALYs lost in low- and middle-income countries. ${ }^{72}$

The second study was conducted by the Australia and New Zealand Working Party on the management and prevention of venous thromboembolism. ${ }^{73}$ This group used incidence data from Western Australia, together with mortality estimates and disability weights derived from the literature, much of which comes from other countries, to estimate the DALYs associated with VTE in Australia for the year 2008. The estimated overall loss for Australia in 2008 was 78,408 DALYs. $^{73}$ The premature mortality (YLL) was $99.7 \%$ of the estimated total burden of disease. ${ }^{73}$

\section{Discussion}

The results of our systematic review of the literature suggest several inferences. First, there is substantial evidence that VTE is associated with a major global burden of disease. Second, most of the level A evidence of this burden comes from the super-region "high income" defined by GBD 2010, although some evidence also comes from the super-region of "Southeast Asia, East Asia, and Oceania" (-Table 1). Third, the evidence of disease burden is primarily based on the incidence of VTE events, and to a lesser extent on the estimated number of deaths for a region or country. Our review identified only one rigorous study estimating the DALYs associated with VTE. ${ }^{72}$ Fourth, there is consistent and strong evidence that the global incidence of VTE increases with increasing age, and is especially pronounced in the elderly (-Table 2 ). This finding has major implications for global health because life expectancy continues to improve in low- and middle-income countries, and these countries continue the transition from infectious diseases to noncommunicable diseases as the major cause of death and disability. Finally, the evidence and the earlier-mentioned inferences lead us to recommend that VTE be measured as a specific cause of death in future efforts of the GBD project. We expand further on these themes in the following paragraphs.

Regarding the annual incidence of VTE, the studies from Western Europe, North America, Australia, and Southern Latin America (Argentina) yielded consistent findings. These studies reported overall annual incidences ranging from 0.75 to 2.69 per 1,000 individuals in the population, with the incidence in most of the studies ranging between 1.07 and 1.83 (-Table 1). The study by Oger ${ }^{21}$ reported that the incidence of VTE was similar to that of myocardial infarction in the same country during a similar time frame. Further, the study by Jha and colleagues ${ }^{72}$ estimated 3.9 million cases of hospital-associated VTE during 1 year among 1.1 billion citizens of high-income countries (3.5 per 1,000 population), and 6.0 million cases among 5.5 billion citizens of low- and middle-income countries ( 1.1 per 1,000 population).$^{72}$ Thus, the aggregate evidence from the literature indicates that VTE is a common condition globally across the spectrum of high-, middle-, and low-income regions.

There was a strong and consistent association of increasing incidence of VTE with increasing age. The annual incidence increased to between 2 and 7 per 1,000 population among those 70 years of age or older in most of the studies, and to between 3 and 12 per 1,000 population among those 80 years of age or older (- Table $\mathbf{2}$ ). This finding has major implications for health care systems and for the care of the elderly. For example, a study of the incidence of VTE among nursing home residents in Kansas reported an incidence of 13 per 1,000 residents per year. ${ }^{70}$ Reardon and colleagues analyzed nursing home records from 19 states in the United States, and found that 1 in 25 admissions had a diagnosis of VTE. ${ }^{56}$ It is likely that the high incidence of VTE in the elderly reflects the high prevalence of comorbid-acquired risk factors in these patients, especially malignancy, heart failure, and immobility associated with surgery or hospitalization for medical illness, which account for the majority of the population attributable risk of VTE in older individuals. In contrast, genetic factors account for only 7 to $22 \%$ of the population attributable risk in the elderly. ${ }^{76}$

The significant burden of VTE is not confined to the elderly, and VTE should not be considered a disease of old age. The annual incidence among individuals in their 40s, 50s, and 60s ranged from 0.2 to 5.3 per 1,000 population (-Table 2 ), with the incidence in the very contemporary studies ${ }^{9,24}$ ranging from 0.8 to 3.9 .

The level A studies from Taiwan, Hong Kong, and Korea reported lower annual incidences of VTE or DVT (ranging from 0.079 to 0.171 per 1,000 population, - Table 1). ${ }^{37-39}$ These results are consistent with the findings of studies in the United States, which reported lower annual incidences of VTE in Asian Americans than in Caucasians and African 
Americans. ${ }^{31}$ There was also a strong association between increasing age and increased incidence in the studies from Hong Kong, Taiwan, and Korea ${ }^{36-38}$ (- Table 2). So, although the overall incidence is lower in individuals of Chinese and Korean ethnicity, their disease burden is not low because of population aging and increased life expectancy. Recent studies undertaken in Asian countries have demonstrated rates of VTE after major surgery and in hospitalized medical patients approaching those observed in Western populations. ${ }^{77}$

The literature review identified limited information on the number of deaths due to VTE. The strongest evidence comes from the study by Cohen and colleagues, who used an incidence-based model in six European countries to estimate that there were 534,454 deaths related to VTE across the European Union in $2004 .^{8}$ A similar approach applied to the data from the United States suggested approximately 300,000 deaths from VTE each year. ${ }^{78,79}$ The direct ascertainment of deaths due to VTE is difficult because of the low rate of autopsy in most countries, and because autopsy studies have consistently demonstrated that PE is often not diagnosed antemortem and that deaths due to PE are frequently misclassified as cardiac deaths. Furthermore, PE may be the primary cause of death, such as in patients with unprovoked VTE, or a secondary (contributing) cause of death, for example, in the cancer patient or the patient with multiple medical conditions. Secondary causes may not always be documented or measured in studies of causes of death. For these reasons, estimates of the number of deaths from VTE based on death certificates or hospital discharge data will underestimate the death burden.

Our review found limited information on the DALYs associated with VTE. The study by Jha and colleagues ${ }^{72}$ provides evidence that VTE causes a major burden of disease across low-, middle-, and high-income countries. VTE was the highest ranked cause of DALYs overall among the seven causes of hospital-associated adverse events. However, because the study evaluated only DALYs related to inpatient adverse events, it underestimates the total contribution of VTE, as a substantial proportion of VTE events occur out of hospital. ${ }^{78}$ Premature death accounts for approximately two-thirds of the DALYs lost due to VTE. ${ }^{72}$ Thus, even in patients with underlying chronic or terminal illness (e.g., advanced heart failure or cancer), VTE causes earlier death for many of these patients.

Disability was responsible for 34\% of the DALYs associated with VTE, ${ }^{72}$ indicating that VTE causes significant YLD because of the nonfatal consequences of DVT and PE. Despite treatment, approximately 10 to $20 \%$ of patients with DVT develop severe postthrombotic syndrome, a chronic disorder that decreases quality of life and reduces the capacity to walk and work. ${ }^{80,81}$.In the most severe cases, patients with postthrombotic syndrome can develop venous ulcers, which are slow to heal and costly for the health care system. ${ }^{80,81}$ Heit and colleagues reported an incidence of venous ulcers of 1.8 per 1,000 population per year. ${ }^{82} \mathrm{PE}$ is associated with chronic thromboembolic pulmonary hypertension in up to $4 \%$ of patients. ${ }^{83}$ Patients with this disorder have varying degrees of respiratory and cardiac impairment. Therefore, the long- term consequences of VTE are associated with considerable disability and are likely to produce significant YLD. Consequently, the disease burden of VTE occurs through both YLL and YLD. Recently, the long-term psychological consequences of PE have been documented to include emotional distress, worry, and anxiety due to uncertainty about whether or when a recurrence might occur, and in some cases, symptoms characteristic of posttraumatic stress disorder. ${ }^{84}$ Therefore, in addition to the physical burden, there is also an emotional burden associated with VTE.

VTE may affect more people than those diagnosed with it. First, current prevention strategies must be applied to large numbers of patients at risk. Most of these patients receive anticoagulant thromboprophylaxis, which is associated with major bleeding in 0.2 to $1.1 \%$ of patients. ${ }^{85-87}$ Patients with thrombosis, particularly if they have a positive family history, are often tested for hereditary or acquired thrombophilic conditions. If abnormalities are found, this testing is sometimes extended to family members, which may lead to medical interventions, and have psychological consequences. The perceived risk of thrombosis affects many more people than those actually afflicted by it.

VTE was not assessed as a cause of death at the disaggregated level in GBD 2010. ${ }^{3,5,6}$ GBD 2010 used three criteria for including causes of death at the disaggregated level: potentially large burden, substantial health policy interest, and the feasibility of measurement. ${ }^{5}$ We believe that VTE meets all of these criteria. The feasibility of evaluating VTE across the global regions is established by the results of the WHO Patient Safety Program. ${ }^{72,74,75}$ The WHO is commended for including VTE among the adverse outcomes assessed in the Patient Safety Program. Future efforts of the GBD study should include evaluation of VTE as a cause of death and the associated DALYs, both for hospital-associated events, which account for up to $60 \%$ of all VTE, ${ }^{78}$ and also for events that occur outside the hospital setting, such as unprovoked VTE.

Prevention is the key to reducing death and disability from VTE. This includes thromboprophylaxis in patients at risk (primary prevention), such as those undergoing surgery or those hospitalized with medical illnesses, ${ }^{10-12}$ and prevention of recurrent thromboembolic events in patients with established DVT or $\mathrm{PE}^{88}$ (secondary prevention). Effective primary prevention is available for most high-risk patient groups. ${ }^{10-12}$ However, a global audit of utilization of primary thromboprophylaxis documented widespread underuse in eligible patients. ${ }^{89}$ There is evidence that a concerted effort by a health system to include VTE risk assessment at the time of hospital admission and the provision of appropriate primary thromboprophylaxis is effective for reducing VTE-related death and readmission with nonfatal VTE ${ }^{90,91}$ The increased implementation of proven, evidence-based primary prevention against VTE should be a global health priority. The safety and simplicity of extended anticoagulant therapy has improved significantly in recent years, ${ }^{88}$ and this approach to secondary prevention has the potential to markedly reduce the burden from recurrent venous thromboembolic events if appropriately implemented on a global scale. Future research may further refine our ability to 
optimize the benefit-to-risk profile of anticoagulant treatment at the individual patient level, and minimize the side effects of prevention. Strengthening the global effort to prevent VTE is consistent with the World Health Assembly's goal of significantly reducing the global burden from noncommunicable diseases by $2025 .^{92}$

In conclusion, this literature review found substantial evidence of a major global disease burden from VTE. Although this burden has been less extensively evaluated than the burden from arterial thrombosis, which includes ischemic heart disease and ischemic stroke, the available evidence indicates a major burden of disease across low-, middle-, and high-income countries. Because many of these events are potentially preventable, more detailed data on the burden due to VTE should be obtained to inform public health policy and resource allocation in health systems, especially in regions where evidence is now limited or lacking, and to evaluate whether the broader and improved implementation of preventive measures will reduce the disease burden.

\section{Disclosure}

No disclosures were requested by the editors.

\section{References}

1 Hunter DJ, Fineberg HV. Convergence to common purpose in global health. N Engl J Med 2014;370(18):1753-1755

2 Jamison DT, Summers LH, Alleyne G, et al. Global health 2035: a world converging within a generation. Lancet 2013;382(9908): 1898-1955

3 Lozano R, Naghavi M, Foreman K, et al. Global and regional mortality from 235 causes of death for 20 age groups in 1990 and 2010: a systematic analysis for the Global Burden of Disease Study 2010. Lancet 2012;380(9859):2095-2128

4 Horton R. GBD 2010: understanding disease, injury, and risk. Lancet 2012;380(9859):2053-2054

5 Murray CJ, Ezzati M, Flaxman AD, et al. GBD 2010: design, definitions, and metrics. Lancet 2012;380(9859):2063-2066

6 Murray CJ, Vos T, Lozano R, et al. Disability-adjusted life years (DALYs) for 291 diseases and injuries in 21 regions, 1990-2010: a systematic analysis for the Global Burden of Disease Study 2010. Lancet 2012;380(9859):2197-2223

7 Feigin VL, Forouzanfar MH, Krishnamurthi R, et al; Global Burden of Diseases, Injuries, and Risk Factors Study 2010 (GBD 2010) and the GBD Stroke Experts Group. Global and regional burden of stroke during 1990-2010: findings from the Global Burden of Disease Study 2010. Lancet 2014;383(9913):245-254

8 Cohen AT, Agnelli G, Anderson FA, et al; VTE Impact Assessment Group in Europe (VITAE). Venous thromboembolism (VTE) in Europe. The number of VTE events and associated morbidity and mortality. Thromb Haemost 2007;98(4):756-764

9 Yusuf HR, Tsai J, Atrash HK, Boulet S, Grosse SD. Centers for Disease Control and Prevention (CDC). Venous thromboembolism in adult hospitalizations-United States, 2007-2009. MMWR Morb Mortal Wkly Rep 2012;61(22):401-404

10 Kahn S, Lim W, Dunn AS, et al; American College of Chest Physicians. Prevention of VTE in nonsurgical patients: antithrombotic therapy and prevention of thrombosis, 9th ed: American College of Chest Physicians Evidence-based Clinical Practice Guidelines. Chest 2012;141(2, Suppl)e195S-226S

11 Gould MK, Garcia DA, Wren SM, et al; American College of Chest Physicians. Prevention of VTE in nonorthopedic surgical patients: antithrombotic therapy and prevention of thrombosis, 9th ed: American College of Chest Physicians Evidence-base Clinical Practice Guidelines. Chest 2012;141(2, Suppl)e227S-277S

12 Falck-Yitter Y, Francis CW, Johanson NA, et al; American College of Chest Physicians. Prevention of VTE in orthopedic surgery patients: Antithrombotic Therapy and Prevention of Thrombosis, 9th ed: American College of Chest Physicians Evidence-based Clinical Practice Guidelines. Chest 2012;141(2, Suppl)e278S-325S

13 Nicolaides AN, Fareed J, Kakkar AK, et al. Prevention and treatment of venous thromboembolism-International Consensus Statement. Int Angiol 2013;32(2):111-260

14 Hald EM, Enga KF, Løchen ML, et al. Venous thromboembolism increases the risk of atrial fibrillation: the Tromso study. J Am Heart Assoc 2014;3(1):e000483

15 Holst AG, Jensen G, Prescott E. Risk factors for venous thromboembolism: results from the Copenhagen City Heart Study. Circulation 2010;121(17):1896-1903

16 Moretti AM, Tafuri S, Parisi D, Germinario C. Epidemiology of pulmonary embolism in Apulia from analysis of current data. Monaldi Arch Chest Dis 2010;73(1):18-24

17 Severinsen MT, Johnsen SP, Tjønneland A, Overvad K, Dethlefsen C, Kristensen SR. Body height and sex-related differences in incidence of venous thromboembolism: a Danish follow-up study. Eur J Intern Med 2010;21(4):268-272

18 Huerta C, Johansson S, Wallander MA, García Rodríguez LA. Risk factors and short-term mortality of venous thromboembolism diagnosed in the primary care setting in the United Kingdom. Arch Intern Med 2007;167(9):935-943

19 Naess IA, Christiansen SC, Romundstad P, Cannegieter SC, Rosendaal FR, Hammerstrøm J. Incidence and mortality of venous thrombosis: a population-based study. J Thromb Haemost 2007; 5(4):692-699

20 Guijarro R, San Román CM, Perelló JI, Nuño E. Efficiency Group of the Internal Medicine Services of Andalusia; Strategic Plan of the SADEMI (Andalusia Society of Internal Medicine). A study of hospital discharges for venous thromboembolism in the south of Spain. An analysis of 19,170 cases from a regional database from 1998 to 2001. Eur J Intern Med 2005;16(4):279-286

21 Oger E. Incidence of venous thromboembolism: a communitybased study in Western France. EPI-GETBP Study Group. Groupe d'Etude de la Thrombose de Bretagne Occidentale. Thromb Haemost 2000;83(5):657-660

22 Nordström M, Lindblad B, Bergqvist D, Kjellström T. A prospective study of the incidence of deep-vein thrombosis within a defined urban population. J Intern Med 1992;232(2):155-160

23 Kierkegaard A. Incidence of acute deep vein thrombosis in two districts. A phlebographic study. Acta Chir Scand 1980;146(4): 267-269

24 Tagalakis V, Patenaude V, Kahn SR, Suissa S. Incidence of and mortality from venous thromboembolism in a real-world population: the Q-VTE Study Cohort. Am J Med 2013;126(9): e13-e21

25 Wiener RS, Schwartz LM, Woloshin S. Time trends in pulmonary embolism in the United States: evidence of overdiagnosis. Arch Intern Med 2011;171(9):831-837

26 Cushman M, Tsai AW, White RH, et al. Deep vein thrombosis and pulmonary embolism in two cohorts: the longitudinal investigation of thromboembolism etiology. Am J Med 2004;117(1): 19-25

27 Stein PD, Kayali F, Olson RE, Milford CE. Pulmonary thromboembolism in Asians/Pacific Islanders in the United States: analysis of data from the National Hospital Discharge Survey and the United States Bureau of the Census. Am J Med 2004; 116(7):435-442

28 Janke RM, McGovern PG, Folsom AR. Mortality, hospital discharges, and case fatality for pulmonary embolism in the Twin Cities: 1980-1995. J Clin Epidemiol 2000;53(1):103-109 
29 Klatsky AL, Armstrong MA, Poggi J. Risk of pulmonary embolism and/or deep venous thrombosis in Asian-Americans. Am J Cardiol 2000;85(11):1334-1337

30 Silverstein MD, Heit JA, Mohr DN, Petterson TM, O'Fallon WM, Melton LJ III. Trends in the incidence of deep vein thrombosis and pulmonary embolism: a 25-year population-based study. Arch Intern Med 1998;158(6):585-593

31 White RH, Zhou H, Romano PS. Incidence of idiopathic deep venous thrombosis and secondary thromboembolism among ethnic groups in California. Ann Intern Med 1998;128(9): 737-740

32 Anderson FA Jr., Wheeler HB, Goldberg RJ, et al. A populationbased perspective of the hospital incidence and case-fatality rates of deep vein thrombosis and pulmonary embolism. The Worcester DVT Study. Arch Intern Med 1991;151(5):933-938

33 Shiraev TP, Omari A, Rushworth RL. Trends in pulmonary embolism morbidity and mortality in Australia. Thromb Res 2013; 132(1):19-25

34 Ho WK, Hankey GJ, Eikelboom JW. The incidence of venous thromboembolism: a prospective, community-based study in Perth, Western Australia. Med J Aust 2008;189(3):144-147

35 Vázquez FJ, Posadas-Martínez ML, Vicens J, González Bernaldo de Quirós F, Giunta DH. Incidence rate of symptomatic venous thromboembolic disease in patients from a medical care program in Buenos Aires, Argentina: a prospective cohort. Thromb J 2013; 11(1):16

36 Jang MJ, Bang SM, Oh D. Incidence of venous thromboembolism in Korea: from the Health Insurance Review and Assessment Service database. J Thromb Haemost 2011;9(1):85-91

37 Lee CH, Lin LJ, Cheng CL, Kao Yang YH, Chen JY, Tsai LM. Incidence and cumulative recurrence rates of venous thromboembolism in the Taiwanese population. J Thromb Haemost 2010;8(7): 1515-1523

38 Cheuk BL, Cheung GC, Cheng SW. Epidemiology of venous thromboembolism in a Chinese population. Br J Surg 2004;91(4): 424-428

39 Woo KS, Tse LK, Tse CY, Metreweli C, Vallance-Owen J. The prevalence and pattern of pulmonary thromboembolism in the Chinese in Hong Kong. Int J Cardiol 1988;20(3):373-380

40 Kröger K, Moerchel Ch, Moysidis T, Santosa F. Incidence rate of pulmonary embolism in Germany: data from the federal statistical office. J Thromb Thrombolysis 2010;29(3):349-353

41 Deitelzweig SB, Johnson BH, Lin J, Schulman KL. Prevalence of clinical venous thromboembolism in the USA: current trends and future projections. Am J Hematol 2011;86(2):217-220

42 Deitelzweig SB, Lin J, Johnson BH, Schulman KL. Venous thromboembolism in the US: does race matter? J Thromb Thrombolysis 2011;31(2):133-138

43 Abdul Sultan A, Tata LJ, Grainge MJ, West J. The incidence of first venous thromboembolism in and around pregnancy using linked primary and secondary care data: a population based cohort study from England and comparative meta-analysis. PLoS ONE 2013; 8(7):e70310

44 Kane EV, Calderwood C, Dobbie R, Morris C, Roman E, Greer IA. A population-based study of venous thrombosis in pregnancy in Scotland 1980-2005. Eur J Obstet Gynecol Reprod Biol 2013; 169(2):223-229

45 Heyl PS, Sappenfield WM, Burch D, Hernandez LE, Kavanaugh VM, Hill WC. Pregnancy-related deaths due to pulmonary embolism: findings from two state-based mortality reviews. Matern Child Health J 2013;17(7):1230-1235

46 Virkus RA, Løkkegaard EC, Bergholt T, Mogensen U, Langhoff-Roos J, Lidegaard $\varnothing$. Venous thromboembolism in pregnant and puerperal women in Denmark 1995-2005. A national cohort study. Thromb Haemost 2011;106(2):304-309

47 Berg CJ, Callaghan WM, Syverson C, Henderson Z. Pregnancyrelated mortality in the United States, 1998 to 2005. Obstet Gynecol 2010;116(6):1302-1309
48 Sharma S, Monga D. Venous thromboembolism during pregnancy and the post-partum period: incidence and risk factors in a large Victorian health service. Aust N Z J Obstet Gynaecol 2008;48(1):44-49

49 Samuelsson E, Hellgren M, Högberg U. Pregnancy-related deaths due to pulmonary embolism in Sweden. Acta Obstet Gynecol Scand 2007;86(4):435-443

50 Wen SW, Huang L, Liston R, et al; Maternal Health Study Group, Canadian Perinatal Surveillance System. Severe maternal morbidity in Canada, 1991-2001. CMAJ 2005;173(7):759-764

51 Fawcus SR, van Coeverden de Groot HA, Isaacs S. A 50-year audit of maternal mortality in the Peninsula Maternal and Neonatal Service, Cape Town (1953-2002). BJOG 2005;112(9):1257-1263

52 Heit JA, Kobbervig CE, James AH, Petterson TM, Bailey KR, Melton LJ III. Trends in the incidence of venous thromboembolism during pregnancy or postpartum: a 30-year population-based study. Ann Intern Med 2005;143(10):697-706

53 Sullivan EA, Ford JB, Chambers G, Slaytor EK. Maternal mortality in Australia, 1973-1996. Aust N Z J Obstet Gynaecol 2004;44(5): 452-457, discussion 377

54 Lindqvist P, Dahlbäck B, Marŝál K. Thrombotic risk during pregnancy: a population study. Obstet Gynecol 1999;94(4):595-599

55 Santosa F, Moysidis T, Moerchel C, Kröger K, Bufe A. Pulmonary embolism in young people. Trends in Germany from 2005 to 2011. Hamostaseologie 2014;34(1):88-92

56 Reardon G, Pandya N, Nutescu EA, et al. Incidence of venous thromboembolism in nursing home residents. J Am Med Dir Assoc 2013;14(8):578-584

57 Schmidt M, Johannesdottir SA, Lemeshow S, et al. Obesity in young men, and individual and combined risks of type 2 diabetes, cardiovascular morbidity and death before 55 years of age: a Danish 33-year follow-up study. BMJ Open 2013;3(4):e002698

58 Sweetland S, Beral V, Balkwill A, et al; Million Women Study Collaborators. Venous thromboembolism risk in relation to use of different types of postmenopausal hormone therapy in a large prospective study. J Thromb Haemost 2012;10(11):2277-2286

59 Moysidis T, Kröger K, Moerchel C, Santosa F, Gröchenig E. Pulmonary embolism in young males and females in Germany: data from the Federal Statistical Office. Blood Coagul Fibrinolysis 2010; 21(6):511-515

60 Lutsey PL, Virnig BA, Durham SB, et al. Correlates and consequences of venous thromboembolism: The Iowa Women's Health Study. Am J Public Health 2010;100(8):1506-1513

61 Spannagl M, Heinemann LA, Dominh T, Assmann A, Schramm W, Schürmann R. Comparison of incidence/risk of venous thromboembolism (VTE) among selected clinical and hereditary risk markers: a community-based cohort study. Thromb J 2005;3:8

62 Samuelsson E, Hägg S. Incidence of venous thromboembolism in young Swedish women and possibly preventable cases among combined oral contraceptive users. Acta Obstet Gynecol Scand 2004;83(7):674-681

63 Mellemkjaer L, Sørensen HT, Dreyer L, Olsen J, Olsen JH. Admission for and mortality from primary venous thromboembolism in women of fertile age in Denmark, 1977-95. BMJ 1999; 319(7213):820-821

64 Kniffin WD Jr, Baron JA, Barrett J, Birkmeyer JD, Anderson FA Jr. The epidemiology of diagnosed pulmonary embolism and deep venous thrombosis in the elderly. Arch Intern Med 1994;154(8): 861-866

65 Gaborit FS, Overvad K, Nørgaard M, Kristensen SR, Tjønneland A, Severinsen MT. Alcohol intake and risk of venous thromboembolism. A Danish follow-up study. Thromb Haemost 2013;110(1):39-45

66 Kunisawa S, Ikai H, Imanaka Y. Incidence and prevention of postoperative venous thromboembolism: are they meaningful quality indicators in Japanese health care settings? World J Surg 2012;36(2):280-286 [ Erratum in World J Surg 2012;36:278-279]

67 White RH, Dager WE, Zhou H, Murin S. Racial and gender differences in the incidence of recurrent venous thromboembolism. Thromb Haemost 2006;96(3):267-273 
68 Beemath A, Skaf E, Stein PD. Pulmonary embolism as a cause of death in adults who died with heart failure. Am J Cardiol 2006; 98(8):1073-1075

69 Petrauskiene V, Falk M, Waernbaum I, Norberg M, Eriksson JW. The risk of venous thromboembolism is markedly elevated in patients with diabetes. Diabetologia 2005;48(5):1017-1021

70 Gomes JP, Shaheen WH, Truong SV, Brown EF, Beasley BW, Gajewski BJ. Incidence of venous thromboembolic events among nursing home residents. J Gen Intern Med 2003;18(11):934-936

71 Stein PD, Matta F, Yaekoub AY. Incidence of vena cava thrombosis in the United States. Am J Cardiol 2008;102(7):927-929

72 Jha AK, Larizgoitia I, Audera-Lopez C, Prasopa-Plaizier N, Waters H, Bates DW. The global burden of unsafe medical care: analytic modelling of observational studies. BMJ Qual Saf 2013;22(10):809-815

73 Access Economics Pty Limited. The Burden of Venous Thromboembolism in Australia. The Australia and New Zealand Working Party on the Management and Prevention of Venous Thromboembolism; 2008

74 Wilson RM, Michel P, Olsen S, et al; WHO Patient Safety EMRO/ AFRO Working Group. Patient safety in developing countries: retrospective estimation of scale and nature of harm to patients in hospital. BMJ 2012;344:e832

75 Aranaz-Andrés JM, Aibar-Remón C, Limón-Ramírez R, et al; IBEAS team. Prevalence of adverse events in the hospitals of five Latin American countries: results of the 'Iberoamerican Study of Adverse Events' (IBEAS). BMJ Qual Saf 2011;20(12):1043-1051

76 Engbers MJ, van Hylckama Vlieg A, Rosendaal FR. Venous thrombosis in the elderly: incidence, risk factors and risk groups. J Thromb Haemost 2010;8(10):2105-2112

77 Angchaisuksiri P. Venous thromboembolism in Asia-an unrecognised and under-treated problem? Thromb Haemost 2011;106(4): 585-590

78 Heit JA. The epidemiology of venous thromboembolism in the community. Arterioscler Thromb Vasc Biol 2008;28(3):370-372

79 Heit J, Cohen AT, Anderson FJ. Estimated annual number of incident and recurrent, fatal and non-fatal venous thromboembolism (VTE) events in the US. Blood 2005;106:267A

80 Kahn SR, Hirsch A, Shrier I. Effect of postthrombotic syndrome on health-related quality of life after deep venous thrombosis. Arch Intern Med 2002;162(10):1144-1148

81 Kachroo S, Boyd D, Bookhart BK, et al. Quality of life and economic costs associated with postthrombotic syndrome. Am J Health Syst Pharm 2012;69(7):567-572
82 Heit JA, Rooke TW, Silverstein MD, et al. Trends in the incidence of venous stasis syndrome and venous ulcer: a 25-year populationbased study. J Vasc Surg 2001;33(5):1022-1027

83 Pengo V, Lensing AW, Prins MH, et al; Thromboembolic Pulmonary Hypertension Study Group. Incidence of chronic thromboembolic pulmonary hypertension after pulmonary embolism. N Engl J Med 2004;350(22):2257-2264

84 Noble S, Lewis R, Whithers J, Lewis S, Bennett P. Long-term psychological consequences of symptomatic pulmonary embolism: a qualitative study. BMJ Open 2014;4(4):e004561

85 Cohen AT, Spiro TE, Büller HR, et al; MAGELLAN Investigators. Rivaroxaban for thromboprophylaxis in acutely ill medical patients. N Engl J Med 2013;368:513-523

86 Goldhaber SZ, Leizorovicz A, Kakkar AK, et al; ADOPT Trial Investigators. Apixaban versus enoxaparin for thromboprophylaxis in medically ill patients. N Engl J Med 2011;365(23): 2167-2177

87 Raskob GE, Gallus AS, Pineo GF, et al. Apixaban versus enoxaparin for thromboprophylaxis after hip or knee replacement: pooled analysis of major venous thromboembolism and bleeding in 8464 patients from the ADVANCE-2 and ADVANCE-3 trials. J Bone Joint Surg Br 2012;94(2): 257-264

88 Wells PS, Forgie MA, Rodger MA. Treatment of venous thromboembolism. JAMA 2014;311(7):717-728

89 Cohen AT, Tapson VF, Bergmann JF, et al; ENDORSE Investigators. Venous thromboembolism risk and prophylaxis in the acute hospital care setting (ENDORSE study): a multinational crosssectional study. Lancet 2008;371(9610):387-394 [ Erratum in Lancet 2008;371:1914]

90 Lester W, Freemantle N, Begaj I, Ray D, Wood J, Pagano D. Fatal venous thromboembolism associated with hospital admission: a cohort study to assess the impact of a national risk assessment target. Heart 2013;99(23):1734-1739

91 Catterick D, Hunt BJ. Impact of the national venous thromboembolism risk assessment tool in secondary care in England: retrospective population-based database study. Blood Coagul Fibrinolysis 2014;25(6):571-576

92 Sixty-sixth World Health Assembly. Follow-up to the political declaration of the high-level meeting of the General Assembly on the prevention and control of non-communicable diseases. Available at: http://apps.who.int/gb/ebwha/pdf_files/WHA66/ A66_R10-en.pdf; Accessed May 27, 2013 